\section{THU0437 ILLNESS PERCEPTION AND ITS CORRELATES IN PATIENTS WITH IN ANCA-ASSOCIATED VASCULITIS - PRELIMINARY REPORT}

A. Masiak ${ }^{1}$, K. Nowicka-Sauer ${ }^{2}$, D. Banaszkiewicz ${ }^{3}$, B. Grygiel-Górniak ${ }^{4}$, M. Komorniczak ${ }^{5}$, A. Hajduk ${ }^{1}$, Z. Zdrojewski ${ }^{1}{ }^{1}$ Clinic of Internal Medicine, Connective Tissue Diseases and Geriatrics, Medical University of Gdansk; ${ }^{2}$ Department of Family Medicine, Medical University of Gdansk; ${ }^{3}$ Department of Statistics, Faculty of Management, Gdansk University, Gdansk; ${ }^{4}$ Department of Rheumatology and Internal Medicine, Medical University of Karol Marcinkowski, Poznan; ${ }^{5}$ Department of Nephrology, Transplantology and Internal Diseases, Medical University of Gdansk, Gdansk, Poland

Background: Illness perception (IP) is one of the most important factors related to health related quality of life, psychological and physical functioning and medical adherence. ${ }^{1,2}$

Objectives: To explore illness perception and its relationship with chosen clinical, socio-demographic and psychological variables in patients with granulomatosis with polyangiitis (GPA) and microscopic polyangiitis (MPA).

Methods: 38 patients $(57.9 \%$ women; median age 57 years; range 18-85; median disease duration: 11.5, range: 1-248 months) with GPA (28 patients) and MPA (10 patients). Inpatients recruited in 3 clinical centres were asked to complete Brief-IIIness Perception Questionnaire (B-IPQ), ${ }^{3}$ Hospital Anxiety and Depression Scale-Modified (HADS-M) and Multidimensional Fatigue Inventory20 (MFI-20). Socio-demographic variables included age, sex, education and marital status. Medical files were reviewed to gather data on disease duration and its activity (assessed using Birmingham Vasculitis Activity Score version 3, BVASv3). $\mathrm{p} \leq 0.05$ was considered significant.

Results: $63 \%$ of patients had active disease as defined by BVASv3. Median total score of B-IPQ was 48.5 points (range 24-64). There were no significant differences in illness perception (B-IPQ total score) between groups according to sex, education and marital status. No significant relationships between IP and age, disease duration and its activity were noted. Significant positive correlations were observed between B-IPQ total score and MFI-20 total score, general, physical and mental fatigue as well as depression, anxiety and irritability (table 1).

Abstract THU0437 - Table 1. Correlation coefficients between studied variables and B-IPQ results.

\begin{tabular}{lc}
\hline Variable & Spearman's r correlations \\
\hline Age & 0.06 \\
Disease duration & -0.02 \\
BVASv3 & 0.00 \\
MFI-20 total & $0.48^{*}$ \\
General fatigue & $0.48^{*}$ \\
Physical fatigue & $0.38^{*}$ \\
Reduced activity & 0.26 \\
Reduced motivation & 0.25 \\
Mental fatigue & $0.34^{*}$ \\
Depression & $0.54^{*}$ \\
Anxiety & $0.53^{*}$ \\
Irritability & $0.35^{*}$ \\
\hline
\end{tabular}

* statistically significant $p \leq 0,05$

Conclusions: In the studied group illness perception was not related to clinical and socio-demographic factors. More negative illness perception was related to higher levels of fatigue, depression, anxiety and irritability. The results suggest that psychotherapeutic interventions seem vital for improving illness perception in this population.

\section{REFERENCES:}

[1] Hagger MS, Orbell S. A meta-analytic review of the common-sense model of illness representation. Psych Health 2003;18:141-84.

[2] Morgan C, McBeth J, Cordingley L, et al. The influence of behavioral and psychological factors on medication adherence over time in rheumatoid arthritis patients: a study in the biologics era. Rheumatology 2015;54:1780-91.

[3] Nowicka-Sauer K, Banaszkiewicz D, Staśkiewicz I, et al. Illness perception in Polish patients with chronic diseases: Psychometric properties of the Brief Illness Perception Questionnaire. J Health Psychol 2015;21:1739-49.

Disclosure of Interest: None declared

DOI: 10.1136/annrheumdis-2018-eular.6860

\section{THU0438 \\ COMPARATIVE STUDY OF INFLIXIMAB VERSUS ADALIMUMAB IN REFRACTORY UVEITIS ASSOCIATED TO CYSTOID MACULAR OEDEMADUE TO BEHÇET'S} DISEASE. MULCITENTER STUDY OF 40 CASES

B. Atienza-Mateo ${ }^{1}$, V. Calvo-Río ${ }^{1}$, J.L. Martín-Varillas ${ }^{1}$, R. Demetrio-Pablo', E. Beltrán ${ }^{2}$, M. Gandía ${ }^{3}$, M. Mesquida ${ }^{4}$, A. Adan ${ }^{4}$, M.V. Hernández $^{4}$, D. Díaz ${ }^{5}$, E. Valls ${ }^{6}$, L. Martinez ${ }^{6}$, M. Cordero ${ }^{7}$, M. Díaz ${ }^{8}$, J.M. Herreras ${ }^{9}$, O. Maiz $^{10}$, A. Blanco ${ }^{10}$, I. Torre ${ }^{11}$, M. García ${ }^{12}$, F. Francisco ${ }^{13}$, S. Insua ${ }^{14}$, R. Almodóvar ${ }^{15}$, O. Ruiz ${ }^{16}$, F. Jiménez ${ }^{16}$, J. Manero ${ }^{16}$, J.M. Nolla ${ }^{17}, \mathrm{M}$. Hernandez ${ }^{18}, \mathrm{M}$. A. González-Gay ${ }^{1}$, R. Blanco ${ }^{1} .{ }^{1}$ Rheumatology and Ophthalmology, Hospital Universitario Marqués de Valdecilla. IDIVAL, Santander, ${ }^{2}$ Rheumatology, Hospital del Mar, Barcelona; ${ }^{3}$ Rheumatology, Hospital puerta del Mar, Cádiz;

${ }^{4}$ Rheumatology, Hospital Clinic, Barcelona; ${ }^{5}$ Ophthalmology, Hospital Clínico San Carlos, Madrid; ${ }^{6}$ Rheumatology and Ophthalmology, Hospital Peset, Valencia;

${ }^{7}$ Rheumatology, Hospital de León, León; ${ }^{8}$ Rheumatology, Hospital Universitario La Fe, Valencia; ${ }^{9}$ Ophthalmology, Hospital Universitario IOBA, Valladolid;

${ }^{10}$ Rheumatology and Ophthalmology, Hospital Universitario de Donostia, San

Sebastián; ${ }^{11}$ Rheumatology, Hospital Universitario de Basurto, Bilbao;

${ }^{12}$ Rheumatology, Hospital Universitario de la Princesa, Madrid; ${ }^{13}$ Rheumatology, Hospital Doctor Negrín, Las Palmas de Gran Canaria; ${ }^{14}$ Rheumatology, Hospital Universitario Santiago de Compostela, A Coruña; ${ }^{15}$ Rheumatology, Hospital Universitario Fundación Alcorcón, Madrid; ${ }^{16}$ Ophthalmology and Rheumatology, Hospital Miguel Servet, Zaragoza; ${ }^{17}$ Rheumatology, Hospital Universitari de Bellvitge, Barcelona; ${ }^{18}$ Ophthalmology, Hospital General Universitario de Valencia, Valencia, Spain

Objectives: To compare the efficacy of infliximab (IFX) versus adalimumab (ADA) as first biologic drug in refractory uveitis with cystoid macular oedema (CME) associated to BD.

Methods: Multicenter study of 40 patients with BD-associated uveitis with $\mathrm{CME}$ refractory or intolerant to standard treatment (corticosteroids and at least one conventional immunosuppressive agent). CME was considered if macular thickness was greater than $300 \mu \mathrm{m}$. Comparative outcome measures were macular thickness, improvement of visual acuity (VA), activity of anterior chamber inflammation and vitritis. Results were expressed as mean $\pm S D$ for variables with a normal distribution, or as median [25th-75th interquartile range- IQR] when not normally distributed. The comparison of continuous variables among time-periods was performed with the Wilcoxon signed rank test.

Results: We selected patients with CME from a cohort of 177 patients with refractory BD-related uveitis $(n=40)$. IFX was used in 15 cases and ADA in 25. No significant differences at baseline were observed between IFX vs ADA groups in sex ( $\sigma^{*} /$ ㅇ $8 / 7$ vs $13 / 12, p=0.93$ ), mean age ( $38 \pm 9$ vs $41 \pm 10$ years, $\left.p=0.53\right)$, HLA-B51 + (10 vs $19, p=0.87$ ), uveitis pattern (panuveitis $67 \%$ vs $80 \%$, posterior uveitis $33 \%$ vs $20 \%, p=0.34$ ), previous conventional treatment (intravenous pulses of methylprednisolone $60 \%$ vs $52 \%, p=0.62$, oral corticosteroids $93 \%$ vs $72 \%, p=0.1$, methotrexate $53 \%$ vs $52 \%$, p=0.93, cyclosporin A $73 \%$ vs $88 \%, p=0.23$, azathioprine $53 \%$ vs $56 \%, p=0.86$, other drugs $47 \%$ vs $68 \%, p=0.18$ ), and combined treatment $(67 \%$ vs $64 \%, p=0.86)$. After 1 year of therapy, ocular remission was achieved in $60 \%$ of cases with IFX and in $76 \%$ of cases with ADA $(p=0.28)$. Regarding CME, $65 \%$ of patients with IFX reached a macular thickness $<250 \mu \mathrm{m}$ vs $87 \%$ of patients with ADA, with no statistically significant differences $(p=0.07)$. Evolution of ocular parameters is shown in the table 1. Only 2 adverse effects were observed, both in ADA group (local rash and bacteremia).

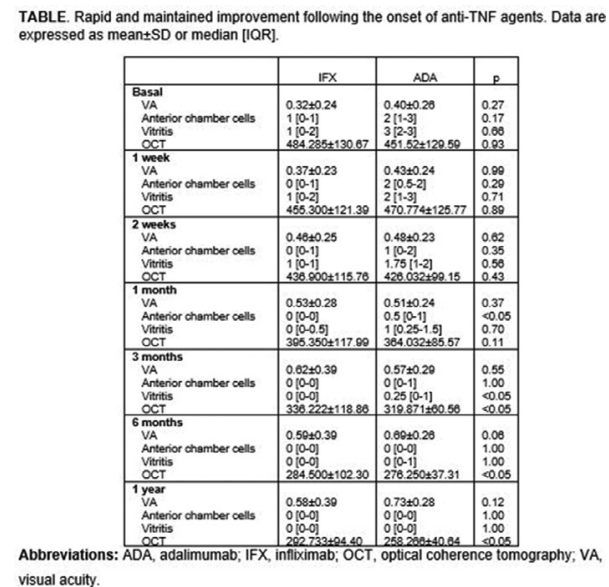

Conclusions: IFX and ADA show a similar efficacy in the treatment of CME in BD-related refractory uveitis. 


\section{REFERENCE:}

[1] Calvo-Río V, Blanco R, Beltran E, Sanchez-Burson J, Mesquida M, Adan A, et al. Anti-TNF- therapy in patients with refractory uveitis due to Behcet's disease: a 1-year follow-up study of 124 patients. Rheumatology (Oxford) 2014;53(12):2223-31.

Disclosure of Interest: None declared

DOI: 10.1136/annrheumdis-2018-eular.3891

\section{THU0439 TOCILIZUMAB IN GIANT CELL ARTERITIS. NATIONAL MULTICENTER STUDY OF 134 PATIENTS OF CLINICAL PRACTICE}

D. Prieto-Peña ${ }^{1}$, J. Loricera ${ }^{1}$, J. Martín-V ${ }^{1}$, M. Calderón-G ${ }^{1}$, V. Aldasoro ${ }^{2}$, M. Varela- $G^{2}, R$. Ibánez-B $B^{2}$, I. Villa ${ }^{3}$, E. Aurrecoechea ${ }^{3}, S$. Castañeda ${ }^{4}$, A. Humbría ${ }^{4}$, E. Díez ${ }^{5}$, C. Moriano ${ }^{5}$, S. Romero-Y ${ }^{6}$, J. Narváez ${ }^{7}$, C. Gómez-A ${ }^{8}$, A. Mera ${ }^{9}$, E. Pérez-P $P^{9}$, R. Dos Santos ${ }^{9}$, C. Barbazán ${ }^{10}$, R. Melero ${ }^{10}$, E. Becerra$\mathrm{F}^{11}$, Á. García $^{11}, \mathrm{M}$. Revenga ${ }^{12}, \mathrm{C}$. Larena ${ }^{12}, \mathrm{E}$. Miguel ${ }^{13}, \mathrm{~N}$. Álvarez- $\mathrm{R}^{14}$, C. Galisteo ${ }^{7}$, F. Sivera ${ }^{15}$, A. Olivé-M ${ }^{16}$, A. Prior ${ }^{16}, M$. Álvarez ${ }^{17}$, L. Marena- $R^{18}$, C. Fernández-L ${ }^{19}$, F. Navarro ${ }^{11}$, E. Raya ${ }^{20}$, N. Ortego ${ }^{20}$, E. Galíndez-A $A^{21}$, B. Arca ${ }^{22}$, S. Fernández ${ }^{22}$, R. Solans- $L^{7}, A$. Conesa $^{23}$, C. Hidalgo ${ }^{24}, C$. Vázquez ${ }^{25}$ J. Román-1 ${ }^{26}$, F. Ortiz- $S^{26}, P$. Lluch ${ }^{27}, S$. Manrique- $A^{28}$, P. Vela ${ }^{11}$, C. Torres- $M^{29}$, J. Nieto ${ }^{30}$, C. Ordas- $\mathrm{C}^{31}$, E. Salgado-P $\mathrm{P}^{32}, \mathrm{C}$. Gómez ${ }^{33}$, J. Toyos ${ }^{34}$, I. Hernández ${ }^{10}$, F. Maceiras- $P^{10}$, N. Fernández- $L^{35}, A$. García ${ }^{20}$, N. Palmou- ${ }^{1}$, V. Calvo-R ${ }^{1}$ C. González-V ${ }^{1}$, L. Domínguez-C ${ }^{1}$, A. Corrales ${ }^{1}$, J. Hernández ${ }^{1}$, M. GonzálezGay ${ }^{1}$, R. Blanco ${ }^{1} .{ }^{1}$ Valdecilla, Santander, ${ }^{2}$ Navarra; ${ }^{3}$ Torrelavega; ${ }^{4}$ Princesa; ${ }^{5}$ León; ${ }^{6}$ Pontevedra; ${ }^{7}$ Barcelona; ${ }^{8}$ Mondragón; ${ }^{9}$ Santiago; ${ }^{10}$ Vigo; ${ }^{11}$ Alicante; ${ }^{12}$ Ramón y Cajal; ${ }^{13} \mathrm{La} \mathrm{Paz} ;{ }^{14} \mathrm{Lugo} ;{ }^{15} \mathrm{Elda} ;{ }^{16} \mathrm{Badalona} ;{ }^{17} \mathrm{Palencia} ;{ }^{18} \mathrm{Alcázar}$, ${ }^{19}$ Coruña; ${ }^{20}$ Granada; ${ }^{21}$ Billbao; ${ }^{22}$ Avilés; ${ }^{23}$ Castellón; ${ }^{24}$ Salamanca; ${ }^{25}$ Zaragoza; ${ }^{26}$ Valencia; ${ }^{27}$ Menorca; ${ }^{28}$ Málaga; ${ }^{29}$ Ávila; ${ }^{30}$ Marañón; ${ }^{31}$ Gijón; ${ }^{32}$ Ourense;

${ }^{33}$ Tenerife; ${ }^{34}$ Sevilla; ${ }^{35}$ Lérida, Spain

Background: Giant cell arteritis (GCA) can be refractory to corticosteroids ${ }^{1-3}$ Tocilizumab (TCZ) demonstrated to be effective in two short-term clinical trials. Objectives: To assess efficacy of TCZ in refractory GCA or with side effects to corticosteroids in clinical practice.

Methods: Multicenter study on 134 patients with GCA in treatment with TCZ due to lack of efficacy and/or unacceptable adverse events of previous therapy. Results: 134 patients $(101 \mathrm{w} / 33 \mathrm{~m})$; mean age of $73.0 \pm 8.8$ years. Main clinical features at TCZ onset were: PMR $(n=73)$, constitutional syndrome $(n=31)$, headache $(n=70)$, visual $(n=28)$ and jaw $(n=14)$ affection. Besides steroids, 98 patients also received immunosuppressive agents. table 1 shows evolution during followup period. After a median follow-up of 12 [3.7-24] months, it was observed a decrease in:a)CRP from $1.7[0.4-3.2]$ to $0.1[0.0-0.3] \mathrm{mg} / \mathrm{dL}$ b)ESR from 33 [14.5-61] to $4^{2-9} \mathrm{~mm} / 1 \mathrm{st}$ hour and c) Prednisone dose from $15^{10-30}$ to 5 [07.5] mg/day. Outcome of patients was:a)discontinuation of TCZ $(n=15)$ due to sustained remission, $b$ )dose reduction due to improvement $(n=17)$ or side effects $(n=11), c)$ withdrawal of TCZ because of side effects $(n=12)$ and $d)$ same dose that at onset $(n=73)$. TCZ had to be discontinued due to: infections, haematological and cardiovascular alterations, neoplasms and heptic toxicity among the most frequent.

Table 1:

\begin{tabular}{|c|c|c|c|c|c|c|}
\hline & $\begin{array}{c}\text { Baseline } \\
\mathrm{n}=134\end{array}$ & $\underset{n=132}{\text { Month 1 }}$ & $\begin{array}{c}\text { Month } 3 \\
n=122\end{array}$ & $\begin{array}{c}\text { Month } 6 \\
\mathrm{n}=99\end{array}$ & $\underset{n=71}{\text { Month }} 12$ & $\underset{n=39}{\substack{\text { Month } \\
n}}$ \\
\hline $\begin{array}{l}\text { Clinical } \\
\text { improvement \% } \\
\text { (n)\# }\end{array}$ & & $83.9 \%(124 / 132)$ & $24.2 \%(115 / 122)$ & $84.0 \%(2498)$ & $92.9 \%(80871)$ & $100 \%$ (301/39) \\
\hline \multicolumn{7}{|l|}{$\begin{array}{l}\text { Laboratory } \\
\text { markers, median } \\
{[\mathrm{IOR}]}\end{array}$} \\
\hline ESR $\left(m m / 1^{5 / / h}\right)$ & $\begin{array}{c}33[14.5-61] " \\
(128)\end{array}$ & $B[2-12]^{\prime \prime}(102)$ & $4[2-7.5] "(116)$ & $4[2-8] "(183)$ & $4[2-8] "(71)$ & $\theta[2-1 \theta] "(3 e)$ \\
\hline CRP (mg/dl) & $\begin{array}{c}1.7(0.4 .322] " \\
(131)\end{array}$ & $0.1[0-0.5]=(88)$ & $0.1(0-0.4]^{\prime \prime}(110)$ & $0.1[0.0 .21 "(102)$ & $0.1[0.0 .2] "(67)$ & $0.1[0-0.4]^{\prime \prime}(39)$ \\
\hline Hemoglobin (g/dl) & $\begin{array}{c}12.3[11.4 \cdot 13.2] " \\
(125)\end{array}$ & $\begin{array}{c}13.2[123-14] " \\
(104)\end{array}$ & $\begin{array}{c}13.5[12.5 \cdot 14.3] " \\
(107)\end{array}$ & $\begin{array}{c}13.6[128.14 .11 " \\
(88)\end{array}$ & $\begin{array}{c}13.3[12.5-14] " \\
(84)\end{array}$ & $\begin{array}{c}13.1[12.3 .13 .9]^{\circ} \\
(36)\end{array}$ \\
\hline $\begin{array}{l}\text { Dose of } \\
\text { corticosteroids } \\
\text { (mg/day), } \\
\text { median [loR] }\end{array}$ & $15\left[(10-30) "{ }^{\prime \prime}(134)\right.$ & $\begin{array}{l}13.77(7.5-201 " \\
(115)\end{array}$ & $8.1[5-12.5] "(120)$ & $5[2.5-7.5] "(97)$ & $2.5[0 .-5] "(71)$ & $0[0.5] "(39)$ \\
\hline
\end{tabular}

Conclusions: TCZ leads to a rapid and maintained improvement in patients with refractory GCA and/or with unacceptable side effects related to corticosteroids. However, the risk of neutropenia and infection should be kept in mind.

\section{REFERENCES:}

[1] Loricera J, et al. Semin Arthritis Rheum 2015;44:717-723.
[2] Loricera J, et al. Clin Exp Rheumatol 2014;32(3Suppl82):S79-89.

[3] Loricera J, et al. Clin Exp Rheumatol 2016; 34 (3 Suppl 97):S44-53.

Disclosure of Interest: None declared

DOI: 10.1136/annrheumdis-2018-eular.4096

\section{THU0440 SOLUBLE CTLA-4 IS ELEVATED IN PATIENTS WITH POLYMYALGIA RHEUMATICA AND CORRELATES WITH VASCULAR INFLAMMATION DETECTED BY PET/CT}

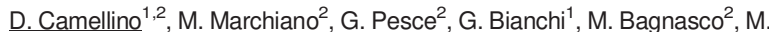
A. Cimmino ${ }^{3}$, D. Saverino ${ }^{4} .^{1}$ Division of Rheumatology, Musculoskeletal System Department, Azienda Sanitaria Locale 3 Genovese, Arenzano; ${ }^{2}$ Autoimmunology Laboratory, Department of Internal Medicine; ${ }^{3}$ Rheumatology Clinic, Department of Internal Medicine; ${ }^{4}$ Autoimmunology Laboratory, Department of Experimental Medicine, University of Genoa, Genoa, Italy

Background: Positron emission tomography has shown the presence of large vessel vasculitis (LVV) in $30 \%-40 \%$ of patients with apparently isolated polymyalgia rheumatica $(P M R)^{[1]}$, but biomarkers associated with the presence of $L V V$ in PMR patients are still lacking. Anti-cytotoxic T lymphocyte antigen-4 (CTLA-4) and its soluble (s) form, resulting from alternative splicing, are well-known immune checkpoint receptor ${ }^{[2]}$ and have shown to play a role both in neoplastic ${ }^{[3]}$ and autoimmune diseases ${ }^{[4]}$. The rationale for studying the involvement of CTLA-4 in PMR is provided by the evidence of drug-induced PMR/giant cell arteritis (GCA) in patients treated with ipilimumab, an anti-CTLA-4 antibody ${ }^{[5]}$.

Objectives: To evaluate the concentration of SCTLA-4 in PMR patients and to correlate it with vascular and joint inflammation.

Methods: Forty consecutive patients with of PMR, of whom 9 also had also GCA, underwent a standardised clinical examination and a PET/CT scan. Arterial and joint uptake of FDG were scored relative to liver and then summed up to obtain a total vascular score (TVS) and a total joint score (TJS). Patients were further subdivided into three groups for the analysis of the correlation with joint and vascular uptake: "vasculitic patients" (with grade-3 uptake in at least one vascular district), patients with intermediate uptake (excluded from this set of analyses), and patients without vasculitis. SCTLA-4, was evaluated by ELISA. Patients without autoimmune diseases served as controls.

Results: SCTLA-4 serum levels were significantly higher in PMR patients than in controls $(p<0.001$, figure 1$)$, although their concentrations did not significantly differ between patients with and without vasculitis. However, SCTLA-4 showed a positive correlation with TVS $(r=0.35, p=0.025)$. figure 1. Panel $A$ : comparison of serum level of SCTLA-4 in patients with PMR and controls (HD: healthy donors). Panel B: correlation between SCTLA- 4 and total vascular score.

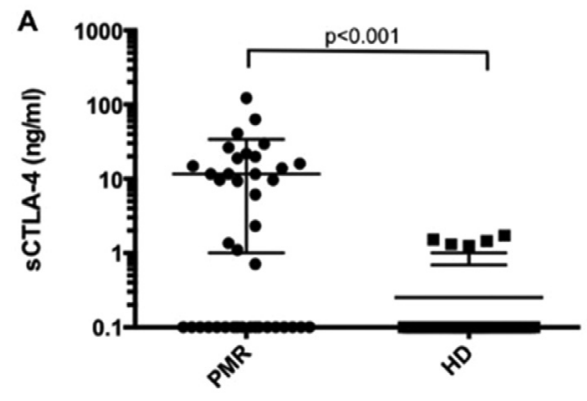

B

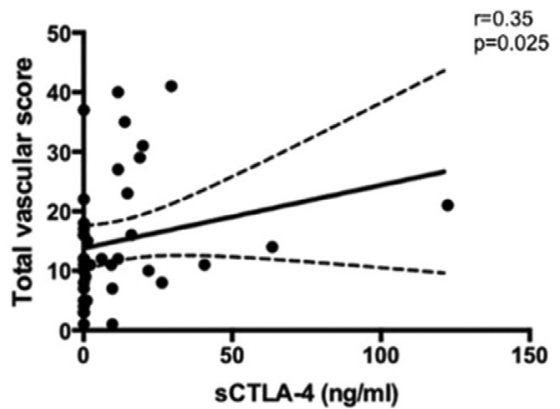

Conclusions: The present study provides the first evidence that serum sCTLA-4 concentration is elevated in PMR patients, and that it correlates with TVS Although the exact mechanisms underlying the upregulation of SCTLA-4 remain 